\title{
A TIME-OF-FLIGHT SPECTROMETER FOR SuperEBIS
}

\author{
A. Kponou, A. Hershcovitch, D. McCafferty, and F. Usack
}

June 2,1994

ALTERNATING GRADIENT SYNCHROTRON DEPARTMENT BROOKHAVEN NATIONAL LABORATORY ASSOCIATED UNIVERSITIES, INC. UPTON, LONG ISLAND, NEW YORK 
This report was prepared as an account of work sponsored by an agency of the United States Government. Nefther the United States Government nor any agency thereof, nor any of their employees, nor any of their contractors, subcontractors, or their employees makes any warranty, express or lmplled, or assumes any legal liability or responsibility for the accuracy, conpleteness, or usefulzess of any information, apparatus, product or process disclosed, or represents that its use would not infringe privately owned rights. Reference herein to any specific comercial product, process, or service by trade nane, trademark, manufacturer, or otherwise, does not necessarily constitute or imply its endorsement, recommendation, or favoring by the Untted States Government or any agency thereof. The views and opinions of authors expressed herein do not necessarily state or reflect those of the United States Government or any agency, contractor, or subcontractor thereof. 
Acceierator Division

Alternating Gradient Synchrotron Department

BROOKHAVEN NATIONAL LABORATORY

Upton, New York 11973

\section{A TIME-OF-FLIGHT SPECTROMETER FOR SUPEIEBIS}

A. Kponou, A. Hershcovitch, D. McCafferty, and F. Usack

\section{INTRODUCTION}

A time-of-flight(TOF) spectrometer for determining ion species and charge states which are produced by ion sources has been constructed. It will be used to analyze the output of SuperEBIS, an Electron Beam Ion Source(EBIS) presently being assembled at BNL. Its design closely follows that of Weisgerber(1), which is based on the original work of Mamyrin(2). The spectrometer has been tested with an ion beam. from a MEVVA(3) ion source using titanium and uranium cathodes.

\section{THEORY}

In the usual TOF spectrometer, a burst of particles is produced by opening a shutter, or by rapidly sweeping the beam across a narrow slit. A detector downstream from the shutter monitors the arrival of the particles. The output of the detector, when displayed on a properly synchronized oscilloscope, is a representation of the spectrum of ion species and/or charge states in the beam. Using the source extraction voltage, the drift length, and the flight times, one should be able to elucidate the spectrum (see Appendix I).

Ions in each 'line' of the spectrum have a small energy spread about some average energy (because they are not created in the same place in the ion source), which causes longitudinal growth of the beam as it drifts toward the detector, thus reducing the resolution of the spectrometer. 
Mamyrin's design uses an electrostatic mirror, adjusted for a small angle of incidence, to rebunch the particles. Rebunching occurs because the ion trajectories in the mirror depend on their energy; more energetic ions spend more time in the mirror. Weisgerber showed that if the length of the mirror is one-half of the drift space between the shutter and mirror entrance, then the flight times of ions in the same 'line' of the spectrum, from the shutcer to the mirror and back to the plane of the shutter, are the same. Thus, the spectrometer has its highest resolution when the detector is also in the plane of the shutter. A schematic representation of the spectrometer is given in Figure 1.

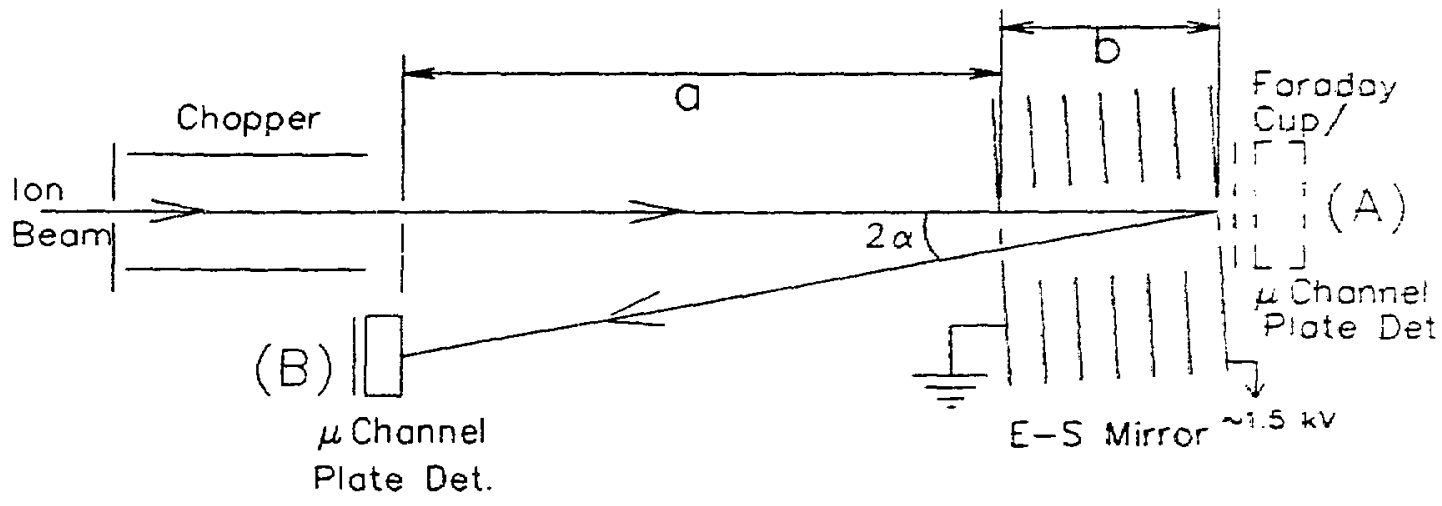

Figure 1. Layout of the time-of-flight spectrometer. $\mathrm{b}=15 \mathrm{~cm} ; \mathrm{a}=2 \mathrm{~b}$; angle $\alpha-2^{\circ}$.

When the spectrometer is mounted on superebis, the MEVVA ion source will be moved to location $A$, for the primary ion beam to be launched into Superebis, located to the left of the Figure.

\section{THE CHOPPER \& DETECTOR}

The chopper and detector assemblies are shown in Figure 2. Chopping of the ion beam was achieved by applying voltage across the parallel plates, one of which was grounded. For initial studies of the beam through the chopper, this was simply + $/-30 \mathrm{~V}$ dc, which was deflected the beam away from the exit slit. For repeated chopping, the dc power supply above and a pulse generator floating on it were used. The amplitude of the pulser was set equal and opposite to the de voltage. The rise time of the pulser was on the order of nanoseconds. Its width determined the time slice of the chopped beam. We observed signals with 1 us pulses.

The detectors used were (1) a Faraday cup with appropriate biasing to suppress detection of secondary 


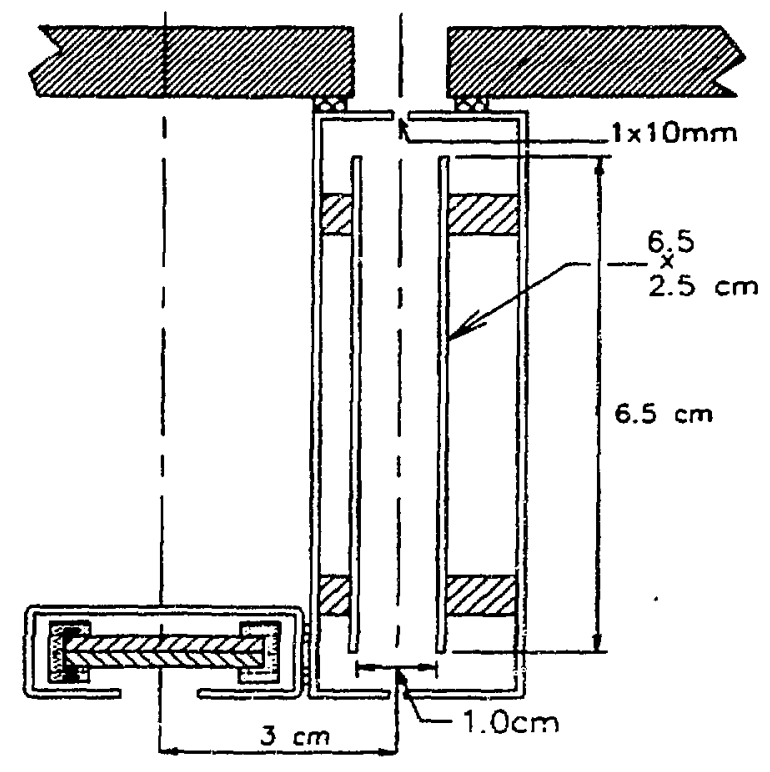

Figure 2. The Chopper and Detector Assemblies.

electrons, and (2) a single microchannel plate (MCP) detector(4) which was salvaged from a discarded piece that had been used in the AGS IPM(5).

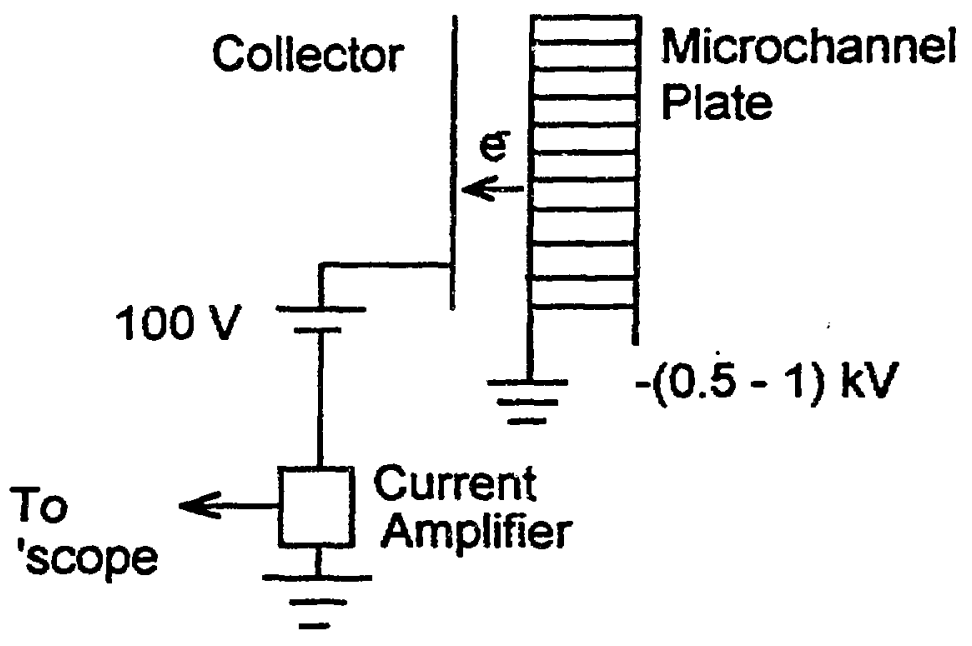

Figure 3. Schematic of the microchannel plate detector.

The biasing scheme used for the detector(Figure 3) allowed us to have the current amplifier at ground potential, thus making the connection to the 'scope straightforward. 


\section{THE ELECTROSTATIC MIRROR}

This consists of a set of equally spaced, concentrically mounted copper plates having circular holes. The front and rear holes are gridded. The plates are biased by $812 \mathrm{k} \Omega$ resistors soldered between them. The voltage on the rear plate is about 1.14 times the ion extraction voltage.

To verify that the ion beam was reaching the mirror, the Faraday Cup/MCP detector combination shown in Figure 1 was substituted for the mirror in the initial studies.

\section{STUDIES AND RESULTS}

with the mirror out, we:

- Established that the ion beam was reaching the mirror by applying a dc voltage to the chopper plates and observing that the signal disappeared at either detector.

- Determined the ion beam profile at the chopper exit slit by sweeping the plate voltage through positive and negative values and noting the transmitted current. After converting voltage to offset from the siit, see Appendix II, a plot of signal vs. offset gave the profile shown in Figure 4. If geometric optics is assumed, the width of the beam at that location should be about $1.3 \mathrm{~mm}$. The observed FWHM is approximately twice this.

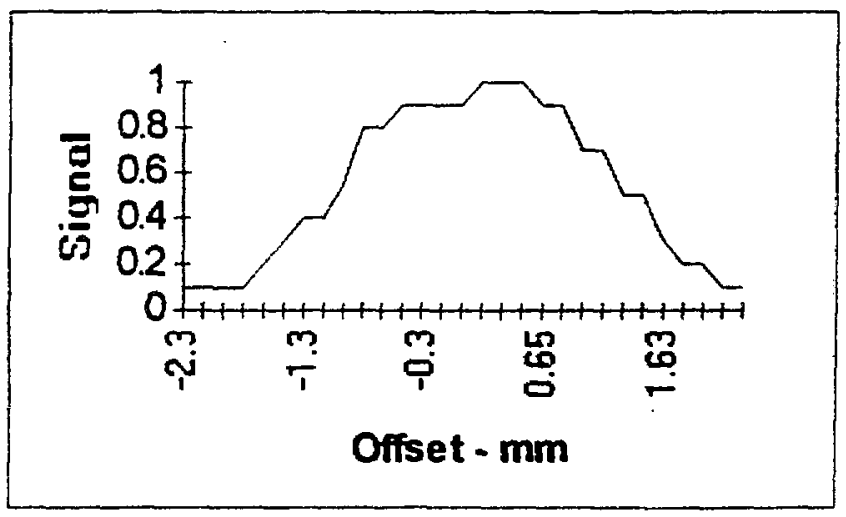

Figure 4 . Ion beam profile at the chopper exit slit. 
After moving the MCP detector to position (B) in Figure 1 , and installing the mirror, we did the following:

-Studied the gain characteristics of the microchannel plate.

-Recorded TOF spectra while varying parameters.

-Studied the displacement of the reflected beam as a function of the mirror voltage.

Figure 5 shows an estimate of the gain of the MCP with voltage. This is a minimum estimate because (1) the value of primary ion beam current used was that measured by the Faraday cup at (A) and (2) the aperture of the MCP at (B) is smaller than that of the Faraday cup.

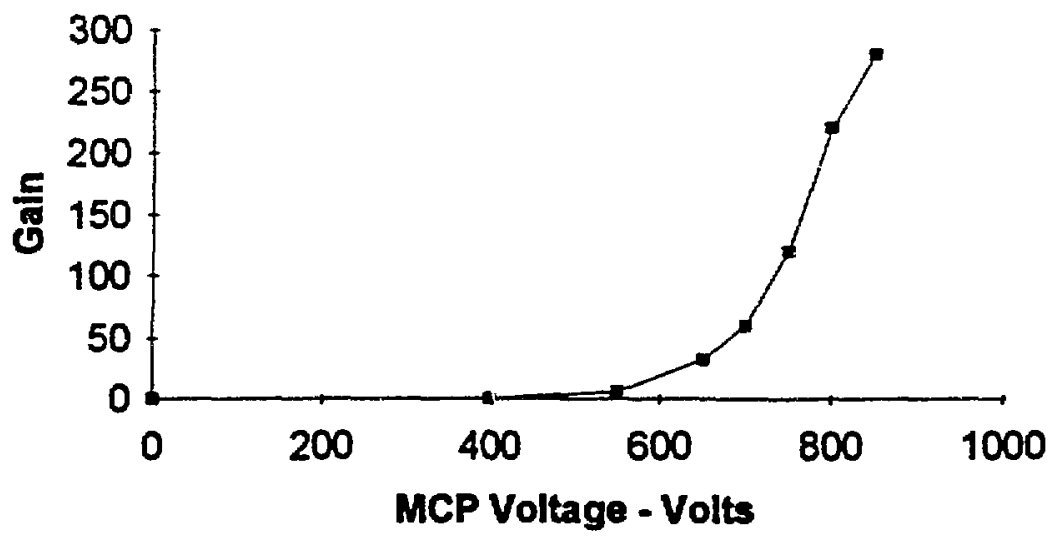

Figure 5. MCP characteristic curve. Amplifier saturated at $900 \mathrm{~V}$.

Figure 6 shows typical TOF spectra for titanium and uranium ions. The expected locations of some charge states are shown in Figure 6(a), for titanium, and rigure 6(c), for uranium. The output of the MEVVA source is therefore predominantly $\mathrm{Ti}^{2} \mathrm{f}$ and $\mathrm{U}^{3+t 06+}$ for these elements. The titanium spectra were obtained with the stand-alone arrangement in Figure 1. The uranium spectrum was obtained with the MEVVA at position $A$ in Figure 1, and the assembly mounted to superEBIS. The ions were detected by another MCP just in front of the electron gun - a straight flight path of about $2 \mathrm{~m}$.

Figure 7 is a plot of the unchopped signal at (B) when the mirror voltage is swept. The effect of changing the mirror voltage is a lateral displacement of the reflected beam, i.e., it moves across the entrance of the MCP while the angle $2 \alpha$ remains the same. The signal is not very sensitive to mirror voltage. 


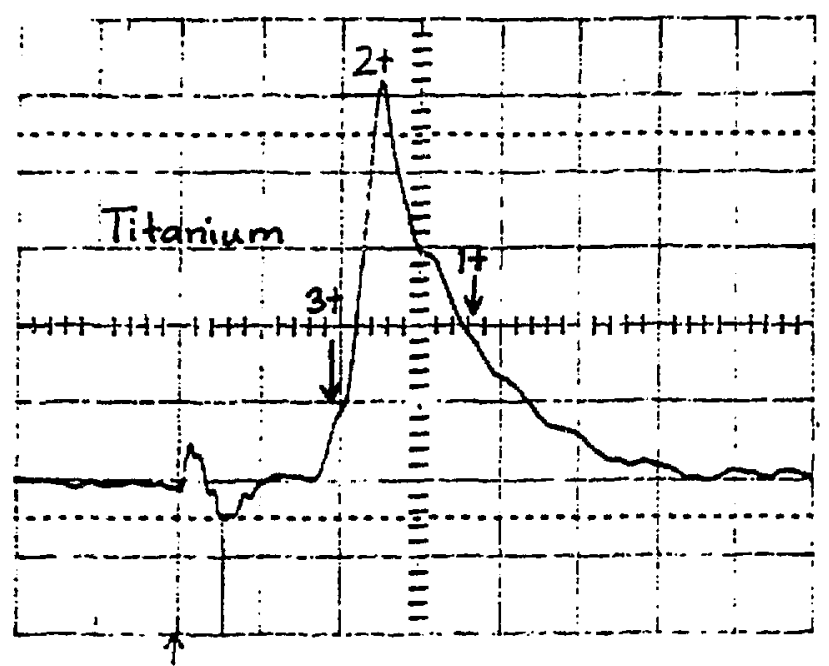

(a)

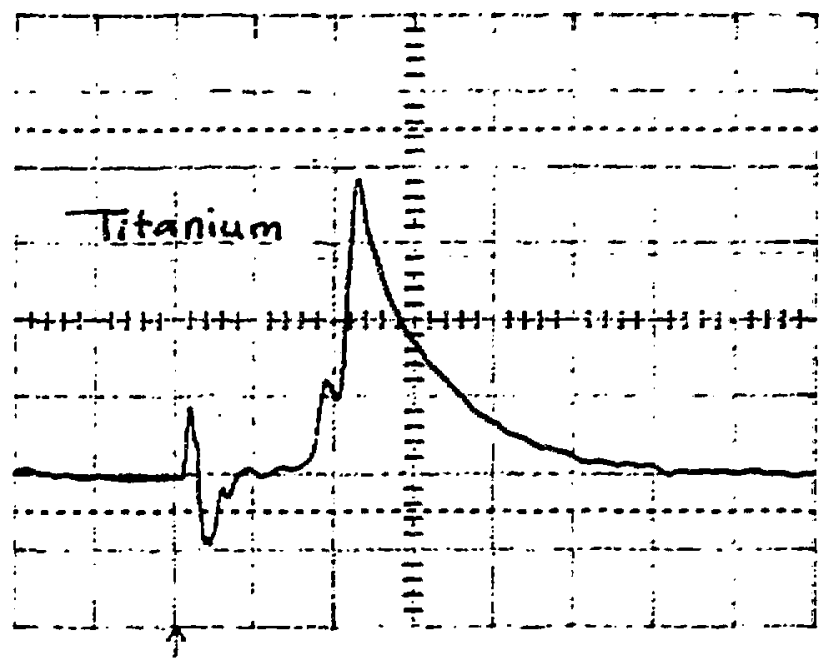

(b)

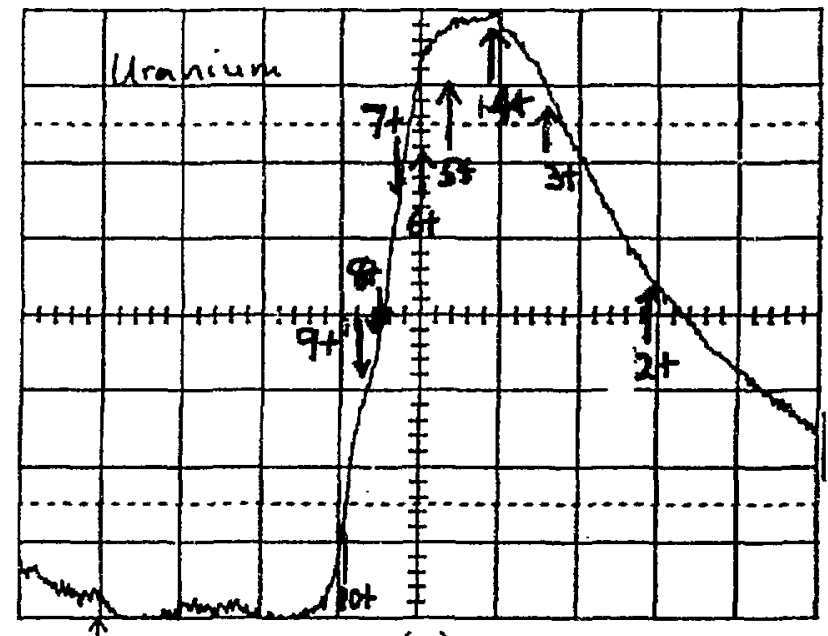

(c)

Figure 6. TOF spectra for titanium and uranium ions produced by the MeVVA ion source.

(a)

$2 \mu \mathrm{s}$

$5 \mu \mathrm{s} / \mathrm{div}$

Horz. sens.

Vert. sens.

MeVVA Extr.

Voltage
$1 \mathrm{~V} / \mathrm{div}$

$1.2 \mathrm{kV}$ (b)

$1 \mu \mathrm{s}$

$5 \mu \mathrm{s} / \mathrm{div}$

$0.5 \mathrm{~V} / \mathrm{div} \quad 2 \mathrm{mV} / \mathrm{div}$

(c)

$2 \mu \mathrm{S}$

$10 \mu \mathrm{s} / \mathrm{div}$

$1.2 \mathrm{kV} \quad 1 \mathrm{kV}$ 


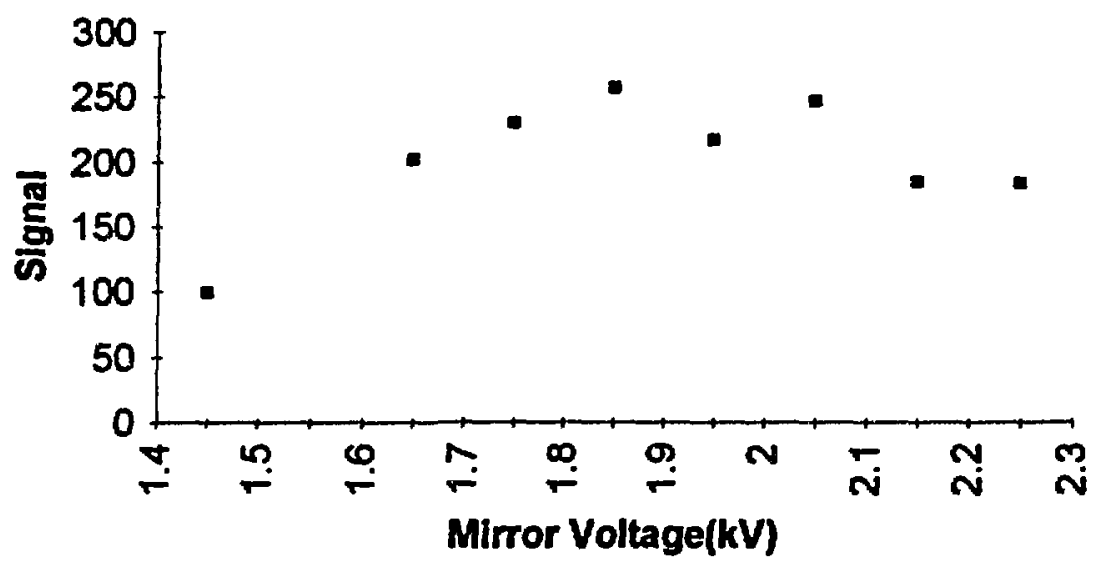

Figure 7. MCP signal(B) vs Mirror voltage.

In Figure 8 , the range, i.e. the distance between the chopper exit slit and MCP entrance aperture, is plotted as a function of mirror voltage. The average slope is: approximately $1.55 \mathrm{~mm} / \mathrm{kv}$. The voltage scan used to obtain the data plotted in Figure 7 corresponds to a lateral displacement of the beam at the detector of about $\pm 7.5 \mathrm{~mm}$ about the optimum. The aperture of the detector was $9.5 \mathrm{~mm}$.

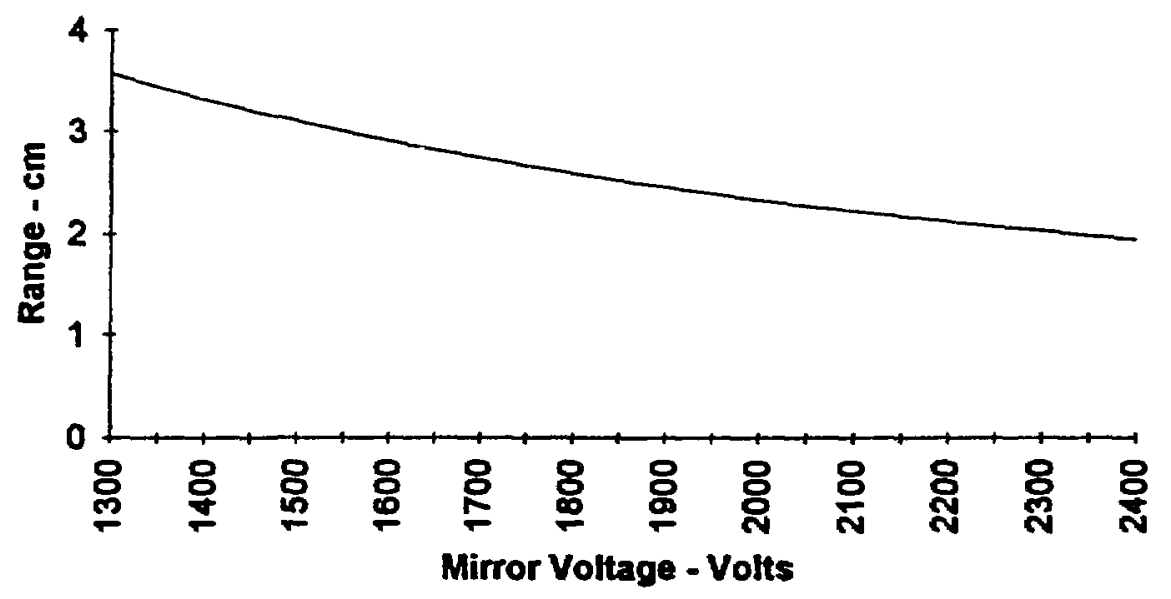

Figure 8. Range of $\mathrm{Ti}$ ions vs mirror voltage. 


\section{CONCLUBIONB}

The spectrometer does not completely resolve the spectrum of charge states from the MEVVA. This may be due to a combination of the slow recovery time of individual channels of the MCP, and the slow response time of the amplifier(6). Using a channeltron multiplier solves the first problem. The amplifier will be replaced with a faster one.

\section{REFERENCES}

[1] W. Weisgerber, Ph.D. Thesis, J.W. Goethe University, Frankfurt/Main. (1979).

[2] B.A. Mamyrin, V.I. Karataev, D.V. Shmikk, and V.A. Zagulin, Sov. Phys.-JEPT, 37, 45 (1973).

[3] I.G Brown, IEEE Trans. Nucl. Sci..NS-32, 1723 (October 1985)

[4] Galileo Electro-optics Corp., Galileo Park, P.O. Box 550, sturbridge, MA, 01566. MCP from a Model 3810 assembly.

[5] A.N. Stillman, R. Thern, and R.L. Witkover, Rev. Sci. Instr., $63(6), 3412$ (1992).

[6] E. Beebe, private communication, 1994. 
APPENDIX I.

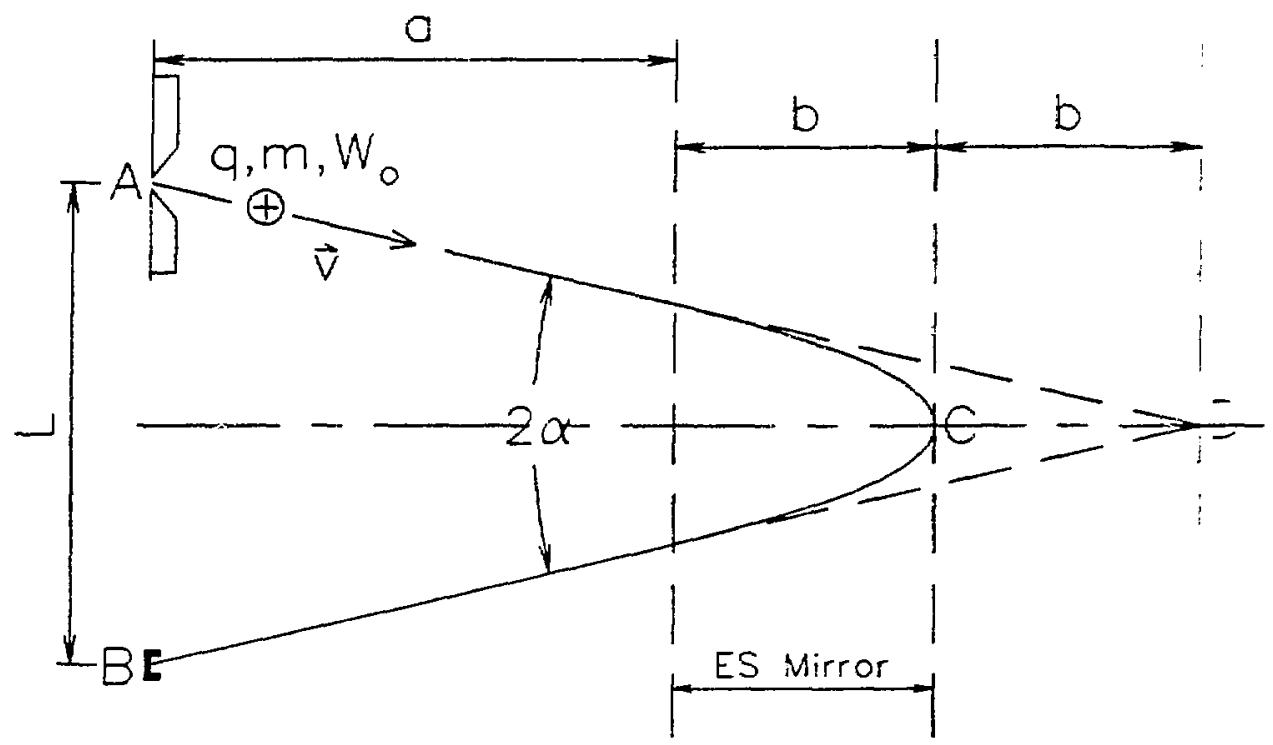

Figure I.I Ion trajectory in TOF spectrometer.

The time-of-flight can be readily calculated if it is realized that the time of flight in the mirror is equal to the time-of-flight along the dashed path (Figure I.1) with velocity $v=\sqrt{\frac{2 W_{0}}{m}}$, where $W_{0}$ is the kinetic energy of the ions in the drift space between the mirror and chopper and detector, and $\mathrm{m}$ is the mass of the ions. That $C D=b$ follows from the standard problem of $a$ projectile in a uniform accelerating field. Since $a=2 b$, for optimum resolution, it follows that the time-offlight is given by the exprssion $4 a \sqrt{\frac{m}{2 W_{0}}}$. 


\section{RPPENDIX II.}

To convert voltage across the chopper plates to beam displacemt at the exit slit, we make use of the following geometrical relationships(Figure II.1):

$$
\mathrm{S}=\frac{1}{4} * \frac{V}{X} * \frac{L^{2}}{d} \quad \text { where } q^{*} e^{*} X \text { is the kinetic energy of }
$$

the ions, $\mathrm{R}=\frac{1}{2} *\left(\frac{L^{2}}{S}+S\right), \Theta=\sin ^{-1}\left(\frac{L}{R}\right)$, and $\mathrm{dS}=\mathrm{dL} * \tan \Theta$.

The total displacement, in mm is $1000 *(S+d S)$.

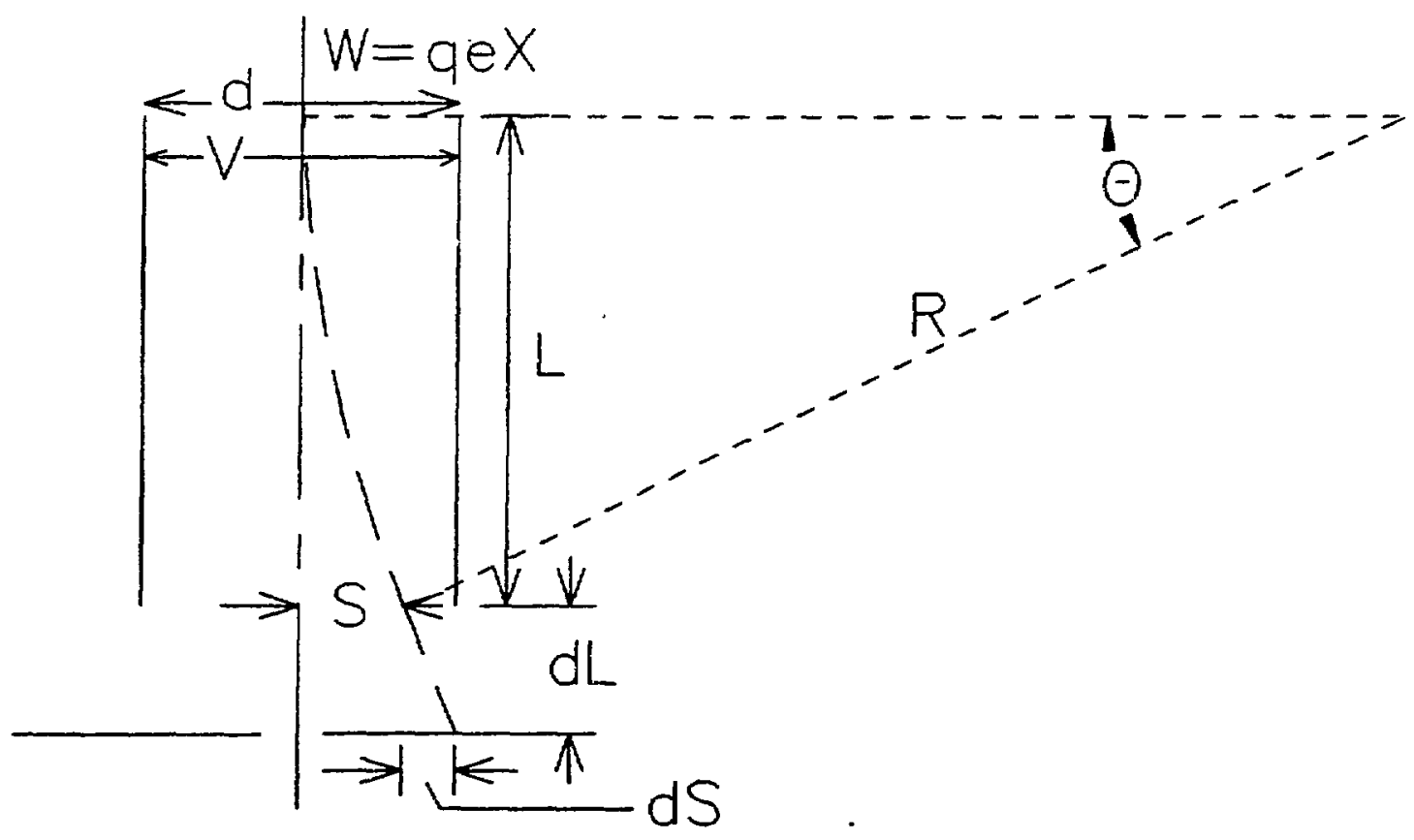

Figure II.1. Ion trajectory in the chopper. 